\title{
Systems biology and bioinformatics help decipher Brucella antigens involved in clinical manifestation of the disease
}

\author{
Menachem Banai ${ }^{1 *}$ and Yongqun $\mathrm{He}^{2,3}$ \\ 1 Department of Bacteriology, Kimron Veterinary Institute, Bet Dagan, Israel \\ 2 Unit for Laboratory Animal Medicine, Department of Microbiology and Immunology, University of Michigan Medical School, Ann Arbor, MI, USA \\ ${ }^{3}$ Center for Computational Medicine and Bioinformatics, University of Michigan Medical School, Ann Arbor, MI, USA \\ ${ }^{*}$ Correspondence: menachemba@moag.gov.il
}

\section{A commentary on}

Antigen-specific acquired immunity in human brucellosis: implications for diagnosis, prognosis, and vaccine development by Cannella, A. P., Tsolis, R. M., Liang, L., Felgner, P. L., Saito, M., Sette, A., Gotuzzo, E., and Vinetz, J. M. (2012) Front. Cell. Inf. Microbio. 2:1. doi: 10.3389/fcimb.2012.00001

Brucellosis, induced by Gram negative bacteria of genus Brucella, is one of a few severe zoonoses with worldwide distribution. Brucella species are partly characterized by their association with a natural host in which they cause last trimester abortions. The Brucella infection of domestic animals (e.g., small ruminants, cattle, and swine) facilitates the spread of the disease in nature and becomes an important factor in sustaining a poor socio-economic standard of living in nomadic populations. Nowadays classification studies have led to the identification of novel species such as B. microti in common voles and red foxes and in soil. The discovery of these Brucella strains has challenged the traditional Brucella taxonomy and minimal standards that characterize the genus members and distinguish them from closer relatives such as Ochrobactrum spp. Given the unappreciated zoonotic potential of brucellosis, debates emerge on the relevance that clinical manifestation may play in classifying a newly identified isolate into the genus Brucella.
Cannella et al. (2012) published an article in this issue that aims at identifying serum antibodies associated with clinical manifestation of human brucellosis. They hypothesized that these antibodies can predict potential Brucella antigenic candidates, and may also have diagnostic, prognostic, and vaccine value. The authors also predicted that by elucidating the antibody profiles of groups of people (including Brucella culture or Rose Bengal assay positive or negative patients, or a naïve population from Brucella-free regions), without knowing specific infection details, common Brucella antigens significant in the clinical manifestation of the disease would be revealed. Based on this hypothesis, many Brucella proteins, including the Type IV secretion system protein VirB8 (Table 1) and VirB5 (Table 3), Outer membrane lipoproteins Omp10, Omp16, and Omp19 (Table 1), and iron metabolism protein Bacterioferritin, were identified to generate antigen-specific antibody immune responses and could be used as potential diagnosis markers or vaccine targets.

This approach assumes that the immune system would respond by a similar antibody repertoire in correlation with a manifested clinical situation. Using a proteome microarray expressing nearly all B. melitensis genes, such a systems biology method systematically analyzes Brucella antibody profiles of human sera in response to physiological and environmental cues.
We believe classical bacteriology, biochemistry, cell biology, and immunology still remain critical disciplines for understanding basic variables affecting host pathogen interactions. Systems biology and bioinformatics have emerged as tools in this field, thereby assisting the continuous cross-talk between researchers in different disciplines and guiding future developments in control and eradication of the disease. Intriguingly, the new tools are not only valuable in clinical studies but also in epidemiological, epizootic, and ecological studies. Computational progress and development of new algorithms could thus be envisioned as an integral part of the new world.

\section{REFERENCE}

Cannella, A. P., Tsolis, R. M., Liang, L., Felgner, P. L., Saito, M., Sette, A., Gotuzzo, E., and Vinetz, J. M. (2012). Antigen-specific acquired immunity in human brucellosis: implications for diagnosis, prognosis, and vaccine development. Front. Cell. Inf. Microbio. 2:1. doi: $10.3389 /$ fcimb.2012.00001

Received: 14 February 2012; accepted: 02 March 2012; published online: 21 March 2012.

Citation: Banai M and He Y (2012) Systems biology and bioinformatics help decipher Brucella antigens involved in clinical manifestation of the disease. Front. Cell. Inf. Microbio. 2:34. doi: 10.3389/fcimb.2012.00034

Copyright (c) 2012 Banai and He. This is an open-access article distributed under the terms of the Creative Commons Attribution Non Commercial License, which permits noncommercial use, distribution, and reproduction in other forums, provided the original authors and source are credited. 